\title{
Índices Morfogênicos e de Crescimento durante o Estabelecimento e a Rebrotação do Capim-Mombaça (Panicum maximum Jacq.) ${ }^{1}$
}

\author{
Carlos Augusto de Miranda Gomide², José Alberto Gomide ${ }^{3}$, Emerson Alexandrino 4
}

\begin{abstract}
RESUMO - Com o objetivo de estimar as características morfogênicas e os índices de crescimento do capim-Mombaça, um ensaio foi conduzido em casa de vegetação. Estudou-se o desenvolvimento das plantas em três crescimentos: o crescimento seminal de estabelecimento (C1), o da brotação após corte ao $16^{\circ}$ dia $(\mathrm{C} 2)$ e $37 \underline{0}$ dia $(\mathrm{C} 3)$ do crescimento de estabelecimento. As variáveis estimadas foram: índices de crescimento [taxa de crescimento relativo (TCR), taxa assimilatória líquida (TAL) e razão de área foliar (RAF)], e os índices morfogênicos [taxa de aparecimento foliar $\left(\mathrm{TA}_{\mathrm{p}} \mathrm{F}\right)$, taxa de alongamento foliar $\left(\mathrm{TA}_{1} \mathrm{~F}\right)$, taxa de expansão da área foliar e taxa de senescência foliar]. Colheitas foram feitas ao longo do desenvolvimento das plantas em cada crescimento considerado: 13, 20, 27, 42, 55,69 e 83 dias após emergência (C1); 0, 3, 6, 10, 17, 24, 38, 52 e 66 dias após o corte aos 16 dias (C2) e 0, 1, 3, 7, 21, 35, 49, 63 e 77 dias após o corte aos 37 dias (C3). Foram observadas três repetições (vasos), segundo delineamento inteiramente casualizado. Altos valores de TAL, RAF e TCR foram observados no início do crescimento seminal (C1) das plantas, caindo assintoticamente com o avanço da idade. O corte aos 37 dias de idade comprometeu o crescimento das plantas expresso em seus valores de $\mathrm{TA}_{\mathrm{p}} \mathrm{F}$, a $\mathrm{TA}_{\mathrm{l}} \mathrm{F}$ e a taxa de expansão da área foliar, RAF, TAL e TCR, sendo observados valores negativos para estes dois últimos índices, nos primeiros dias de brotação. A baixa demanda respiratória e a alocação de fotoassimilados para o crescimento foliar garantiram às plantas cortadas aos 16 dias, balanço positivo de carbono, possibilitando sua rápida recuperação.
\end{abstract}

Palavras-chave: demanda respiratória, taxa assimilatória líquida, taxa de alongamento foliar, taxa de aparecimento foliar, taxa de crescimento relativo, razão de área foliar

\section{Morphogenic Traits and Growth Indices during the Establishment and Regrowth of Mombaçagrass (Panicum maximum Jacq.)}

\begin{abstract}
A trial was carried out in green-house to estimate morphogenic traits and growth indices of Mombaçagrass development. Three growths were considered: the seminal, establishment growth $(\mathrm{G} 1)$ and the regrowths following a clipping taken on the $16^{\text {th }}(\mathrm{G} 2)$ and $37^{\text {th }}(\mathrm{G} 3)$ days of the seminal growth. The variables assessed were the growth indices: relative growth rate (RGR), net assimilation rate (NAR), leaf area ratio (LAR), and the rates of leaf appearance, elongation, expansion and senescence. Accordingly, harvests were taken at the ages of: 13, 20, 27, 42, 55, 69 and 83 day of the seminal growth (G1); 0, 3, 6, 10, 17, 24, 38, 52 and 66 day of the $2^{\text {nd }}$ regrowth (G2) and $0,1,3,7,21,35,49,63$ and 77 day of the $3^{\text {rd }}$ growth (G3). There were three replications (pots) per treatment in a completely randomized design. Figures for NAR, LAR and RGR were high during early seminal growth but declined assynthotically as plant aged. Initial values for these indices were higher in the seminal growth as compared to the 2 regrowths. Cutting taken on the $37^{\text {th }}$ day of the seminal growth hindered the initial growth of the plants regarding leaf appearance and elongation rates, LAR, NAR and RGR. The latter two indices which had negative values during early regrowth, were recovered by the $16^{\text {th }}$ regrowth day.
\end{abstract}

Key Words: leaf appearance rate, leaf area ratio, leaf elongation rate, net assimilation, relative gowth rate, respiratory demand

\section{Introdução}

As plantas captam energia luminosa para seu crescimento, por intermédio do processo fotossintético, reduzindo o $\mathrm{CO}_{2}$ atmosférico a compostos orgânicos essenciais à manutenção de sua biomassa, bem como à formação de novos tecidos. Dessa forma, a planta acumula biomassa durante o seu crescimento segundo a curva sigmoidal, na qual inicialmente se observa um crescimento exponencial, seguido por uma fase de ganhos lineares e finalmente a fase de incrementos decrescentes. Este padrão da curva decorre do balanço entre disponibilidade e demanda de carbono experimentado pela planta. Fatores de meio e de manejo, condicionando características morfogênicas e estruturais do dossel, determi-

\footnotetext{
${ }^{1}$ Parte da Tese de Doutorado do primeiro autor, financiada pela FAPEMIG.

2 Pesquisador da EMBRAPA Gado de Leite - Av. Beira Mar, 3250, CEP: 49001-970, Aracaju - SE (cagomide@cpatc.embrapa.br).

3 Pesquisador IA do CNPq - DZO, Campus da UFV, Viçosa-MG (jagomide@ufv.br).

${ }^{4}$ Doutorando do DZO/UFV, Campus da UFV, Viçosa-MG (ealexandrino@bol.com.br).
} 
nam o acúmulo de biomassa, ou seja, o crescimento do relvado (Chapman \& Lemaire, 1993).

A análise de crescimento possibilita a estimativa de taxas de crescimento que quantificam este balanço em determinado momento ou intervalo de tempo de interesse (Radford, 1967; Harper, 1977; Beadle, 1993). Esta é uma ferramenta bastante valiosa no entendimento das adaptações da planta sob diferentes condições de meio e manejo. A taxa de crescimento relativo (TCR) representa o incremento em peso de matéria seca por peso de matéria seca já existente, num dado intervalo de tempo $\left(\mathrm{g} \cdot \mathrm{g}^{-1} \cdot \mathrm{tempo}^{-1}\right)$. Ela pode ser obtida pelo produto da taxa assimilatória líquida (TAL) pela razão de área foliar (RAF), o que a torna um importante índice do crescimento vegetal, pois combina um fator fisiológico (TAL) e outro morfológico (RAF) (Poorter, 1989).

A TAL representa o balanço fotossíntese-respiração (Lambers, 1987; Lambers et al., 1989, Kraus et al., 1989) podendo ser positiva ou negativa, em função das condições a que a planta é submetida (Lawlor, 1995).

A respiração tem sido separada, funcionalmente, em respiração de crescimento e de manutenção. A respiração de crescimento concorre para a síntese de nova biomassa, e é proporcional à taxa fotossintética líquida, enquanto a de manutenção concorre para a reciclagem de compostos já existentes e é proporcional à biomassa vegetal (Hay \& Walker, 1989, Krauss et al., 1989; Robson, 1973). As perdas respiratórias são extremamente variáveis, dependendo das condições de meio e manejo, podendo alcançar até $60 \%$ do carbono fixado (Krauss et al., 1989). Em se tratando de gramíneas sob pastejo, interessam os dados de Parsons \& Penning (1988), que relatam que 50\% do carbono fixado é consumido na respiração da planta e no crescimento radicular.

O rendimento forrageiro ou a matéria seca produzida é determinada pelo total de radiação fotossinteticamente ativa (RFA) absorvida e pela eficiência de conversão da energia em matéria seca. Segundo Lawlor (1995), o rendimento forrageiro guarda maior correlação com características estruturais do dossel do que com a eficiência fotossintética das folhas, o que destacaria o papel da RAF para a determinação da TCR. Entretanto, a importância relativa dos componentes TAL e RAF na determinação da TCR é controvertida e parece ser dependente do tipo de estudo conduzido.

As variações observadas na TCR de feijão-fava de um ano para o outro foram atribuídas mais à TAL do que à RAF (Costa et al., 1997). Já Poorter et al., (1989) consideram a RAF o principal componente na determinação da TCR. Paralelamente, Beadle (1993), corroborando com Lawlor (1995), também atribui maior importância do índice de área foliar (IAF) relativamente à TAL como fator determinante da taxa de crescimento cultural (TCC). Por outro lado, Potter \& Jones (1976), estudando o efeito de variações da temperatura de crescimento de nove espécies vegetais, encontraram que o crescimento foi mais sensível a mudanças na partição da área foliar ou na taxa relativa de expansão de área foliar do que alterações na TAL.

Avaliando quatro cultivares de Panicum maximum, dentre elas a cultivar Mombaça, Gomide e Gomide (1999) observaram comportamentos semelhantes das curvas de TAL, RAF e TCR, e atribuíram igual importância às duas primeiras taxas para a configuração da curva de TCR em função das idades.

$\mathrm{O}$ conhecimento dos índices de crescimento acima referidos são extremamente importantes na interpretação das respostas das plantas ao meio e/ou manejo. Conquanto sua visualização prática seja tarefa impossível, sua relação com variáveis mais objetivas como número de folhas expandidas e número de folhas vivas por perfilho, obtidos via estudos de morfogênese das espécies, pode ser uma alternativa válida a fim de facilitar a interpretação de práticas de manejo. Assim, o número de folhas emitidas por perfilho tem se mostrado um critério aplicável na determinação do momento de desfolha em gramíneas forrageiras (Fulkerson et al., 1999; Fulkerson \& Slack, 1995).

Objetivou-se com este trabalho avaliar informações morfogênicas, principalmente, taxas de aparecimento, alongamento e senescência foliares, e fisiológicas (índices de crescimento) do capim-mombaça em três períodos de crescimento, e relacioná-las de modo a obter subsídios para a orientação do manejo desta espécie.

\section{Material e Métodos}

Sementes de capim-mombaça (Panicum maximum) foram colocadas em vasos de PVC, de 30 $\mathrm{cm}$ de diâmetro, com capacidade para $14 \mathrm{~kg}$ de solo, em número suficiente para garantir um mínimo de quatro plantas por vaso, após desbaste.

As características químicas e físicas do solo utilizado para enchimento dos vasos foram: Latossolo Vermelho Escuro, textura argilosa, pH em água - 5,9;

\footnotetext{
R. Bras. Zootec., v.32, n.4, p.795-803, 2003
} 
P e K - respectivamente, 7,4 e 107,0 mg.dm ${ }^{-3}$; alumínio - 0,0 cmolc. $\mathrm{dm}^{-3} ; \mathrm{Ca}+\mathrm{Mg}-4,1 \mathrm{cmolc} \cdot \mathrm{dm}^{-3} ; \mathrm{H}+$ Al - 3,3 cmolc. dm ${ }^{-3}$; CTC efetiva $-4,37$ cmolc. dm $^{-3}$ e saturação de bases - $57 \%$. O solo foi corrigido e enriquecido com adubação fosfatada de superfosfato simples, equivalente a $200 \mathrm{mg} \cdot \mathrm{dm}^{-3}$ de fósforo, de modo a garantir o perfeito crescimento das plantas ao longo do período experimental. Também foi feita adição de areia, na proporção 1 parte de areia para 4 partes de solo, para facilitar a recuperação de raízes no momento das colheitas. As irrigações foram feitas a cada dois dias, garantindo ótimas condições de crescimento às plantas. Adubação nitrogenada e potássica dos vasos foi realizada quinzenalmente, via água de irrigação, à base de $30 \mathrm{mg} \cdot \mathrm{dm}^{-3}$ de nitrogênio e potássio, respectivamente, sulfato de amônia e cloreto de potássio.

Estudaram-se três crescimentos: o seminal (C1) e dois crescimentos de rebrota ( $\mathrm{C} 2$ e $\mathrm{C} 3)$, estabelecidos após corte, realizado a $8 \mathrm{~cm}$ do solo, respectivamente, aos 16 e 37 dias após emergência, correspondentes a momentos de alta e baixa TAL (Gomide \& Gomide, 1999), como também início e estabilização da senescência foliar e diferente número de perfilhos por planta.

Colheitas foram feitas ao longo do desenvolvimento das plantas em cada período considerado. Assim, a avaliação do $\mathrm{C} 1$ correspondeu às idades de: 13, 20, 27 , 42, 55, 69 e 83 dias após emergência. Já durante o C2, as plantas foram colhidas às idades de $0,3,6,10,17$, $24,38,52$ e 66 dias após o corte; e no $\mathrm{C} 3$, às idades de $0,1,3,7,21,35,49,63$ e 77 dias após o corte.

Também no momento das colheitas, o corte foi realizado a $8 \mathrm{~cm}$ do solo, sendo a parte aérea levada para o laboratório para separação e processamento das amostras. O solo do vaso foi lavado com jato d'água sobre peneira para recuperação das raízes, que também foram levadas à estufa para secagem. A cada idade de colheita, foi feita a separação dos componentes folha verde, colmo, material morto e raízes.

As plantas dos últimos vasos colhidos no período de estabelecimento, à idade de 83 dias, serviram para o estudo das características morfogênicas. Dessa forma, duas vezes por semana, ao longo de todo seu crescimento, foram feitas observações quanto ao aparecimento, alongamento e senescência de folhas e perfilhamento, para se estimar as respectivas taxas e inferir sobre a condição das plantas durante seu desenvolvimento e no momento dos cortes. Também, durante as duas rebrotações foi feito o acompanha- mento de tais características em perfilhos marcados com anéis coloridos.

Às idades de corte, a área das folhas verdes foi medida em sistema de análise de imagem - DIAS (Delta - T, Cambridge, Inglaterra), e o material devidamente separado foi secado em estufa de ventilação forçada a $650 \mathrm{o}$ por 72 horas, sendo pesado em seguida. De posse dos dados de peso seco da planta inteira, além de peso e área foliar, estimou-se, em função das idades, os seguintes índices fisiológicos: taxa assimilatória líquida média, taxa média de crescimento relativo e razão de área foliar (Beadle, 1993). Para tanto, considerou-se os dados obtidos entre duas colheitas consecutivas conforme as fórmulas a seguir:

$\overline{\mathrm{TCR}}=(\ln \mathrm{M} 2-\ln \mathrm{M} 1) / \mathrm{t}$

$\overline{\mathrm{TAL}}=[(\mathrm{M} 2-\mathrm{M} 1) / \mathrm{t}) \mathrm{X}(\ln \mathrm{AF} 2-\ln \mathrm{AF} 1) /(\mathrm{AF} 2-\mathrm{AF} 1)]$ $\overline{\mathrm{RAF}}=[(\mathrm{AF} 2-\mathrm{AF} 1) /(\mathrm{M} 2-\mathrm{M} 1) \mathrm{X}(\ln \mathrm{M} 2-\ln \mathrm{M} 1) /(\ln \mathrm{AF} 2-\ln \mathrm{AF} 1)]$ em que: $\mathrm{M} 2$ e $\mathrm{M} 1$ = Respectivamente, massa seca total final e inicial da planta no intervalo considerado; $\mathrm{AF} 2$ e $\mathrm{AF} 1$ = Respectivamente, área foliar final e inicial da planta no intervalo considerado; $\mathrm{t}=$ tempo, em dias, do intervalo considerado.

A partir dos valores de área foliar, diâmetro dos vasos e espaçamento entre os mesmos, estimou-se o índice de área foliar (IAF).

Durante o desenvolvimento das plantas, mediu-se a intercepção da radiação fotossinteticamente ativa nos crescimentos de estabelecimento $(\mathrm{C} 1)$ e rebrota após corte aos 16 dias de idade (C2). Para tanto, foram feitas leituras da radiação incidente e da radiação transmitida, utilizando-se o medidor de luz LI250 (LI-COR, Nebraska, EUA) e a linha de sensores quânticos LI 190 SA (LICOR, Nebraska, EUA) colocada acima do dossel e ao nível do solo, respectivamente.

O ensaio foi conduzido segundo o delineamento inteiramente casualizado com três repetições por crescimento, utilizado-se portanto um total de 75 vasos. O trabalho foi desenvolvido em casa de vegetação da Unidade de Crescimento de Plantas (UCP) da Universidade Federal de Viçosa.

Os dados foram submetidos à análise de variância, sendo as médias de tratamentos comparadas pelo teste Tukey a $5 \%$ de probabilidade. O modelo matemático utilizado foi:

$$
\mathrm{Y}_{\mathrm{ij}}=\mu+\mathrm{T}_{\mathrm{i}}+\mathrm{E}_{\mathrm{ij}}
$$

em que: $Y_{i j}=$ observação relativa ao $j^{o}$ vaso do $i^{o}$ tratamento; $\mu=$ média geral; $\mathrm{T}_{\mathrm{i}}=$ efeito do io tratamento, $\mathrm{i}=1,2,3$ crescimentos; $\mathrm{E}_{\mathrm{ij}}=$ erro experimental, efeito do jo vaso referente ao $i^{0}$ crescimento. 


\section{Resultados e Discussão}

Às idades de 16 e 37 dias após emergência, as plantas apresentaram características bastante diferentes (Tabela 1). À medida que a planta se desenvolve, novas folhas e perfilhos são lançados, incrementando a área foliar e o peso da planta.

Aos 16 dias de idade, a parte aérea representou $86 \%$ da biomassa total, sendo $66 \%$ desta constituída por folhas. Esta predominância da parte aérea e principalmente de folhas, nas duas primeiras semanas de crescimento seminal evidencia que o meristema apical e as folhas em expansão são os drenos preferenciais nesta fase inicial de desenvolvimento. Este intenso desenvolvimento foliar decorre do aumento no número de folhas.perflho-1 ${ }^{-}$Já aos 37 dias, $92 \%$ do peso seco da planta advém da parte aérea, porém, a participação de folhas cai para $54 \%$ da parte aérea, destacando o aumento na participação da fração pseudocolmo. De fato, neste período de 21 dias do crescimento seminal o percentual de colmo na planta passou de 29 para $42 \%$, enquanto as frações folha e raiz caíram 7 e 6 unidades percentuais, respectivamente (Tabela 2).

Da Tabela 1, tem-se que o sistema radicular experimentou incremento de cinco vezes, em quanto a parte aérea decuplicou seu peso, sendo que a fração pseudocolmo respondeu pela maior parte deste incremento, crescendo 13 vezes dos 16 aos 37 dias, enquanto as frações raiz e folha tiveram um crescimento de 5 e 8 vezes, respectivamente. Isto explica os incrementos das relações PA/SR e queda da relação lâmina/colmo nesse período (Tabela 1). Estas alterações nas diferentes frações da planta refletem momentânea alocação preferencial de assimilados para o pseudocolmo. Assim, embora a maior relação PA/SR à idade de 37 dias possa, à primeira vista, indicar maior proporção de folhas nestas plantas, na realidade grande parte do peso da parte aérea nesta idade advém da fração colmo. A maior razão de peso foliar aos 16 dias, juntamente com sua maior relação folha/ colmo comprovam esta condição (Tabela 1). Tem-se portanto, uma eliminação proporcionalmente maior de folhas com o corte realizado à idade de 16 dias.

O número de folhas vivas.perfilho ${ }^{-1}$, estável em 3 para capim-mombaça (Gomide \& Gomide, 2000), foi atingido à idade de 37 dias, e contrastou com as 5,3 folhas vivas.perfilho ${ }^{-1}$ aos 16 dias, refletindo a ocorrência de morte e senescência das primeiras folhas entre as duas idades consideradas. Esta condição, juntamente com a estabilização dos índices de crescimento (Tabela 4), era de interesse para avaliação dos tratamentos.

O comprimento acumulado de folhas verdes/ perfilho principal observado aos 37 dias é superior àquele aos 16 dias apesar do menor número de folhas verdes/perfilho. Tal fato decorre do aumento no tamanho das folhas à medida que elas se sucedem no perfilho. Assim, maiores comprimentos são observados em folhas de nível de inserção intermediário no

Tabela 1 - Características das plantas de capimMombaça às idades de 16 e 37 dias, após emergência

Table 1 - Mombaçagrass plants traits on the 16 and $37^{\text {th }}$ day of growth following emergence

\begin{tabular}{|c|c|c|}
\hline \multirow[b]{2}{*}{$\begin{array}{l}\text { Idade (dias) } \\
\text { Age (days) }\end{array}$} & \multicolumn{2}{|c|}{$\begin{array}{c}\text { Característica } \\
\text { Trait } \\
\end{array}$} \\
\hline & 16 & 37 \\
\hline $\begin{array}{l}\text { Peso da planta inteira }(\mathrm{g}) \\
\text { Whole plant weight }\end{array}$ & $1,42^{\mathrm{B}}(0,606)$ & $14,56^{\mathrm{A}}(7,25)$ \\
\hline $\begin{array}{l}\text { Parte aérea }(\mathrm{g}) \\
\text { Aerial part }\end{array}$ & 1,22 & 13,37 \\
\hline $\begin{array}{l}\text { Folhas }(\mathrm{g}) \\
\text { Leaves }\end{array}$ & 0,81 & 7,31 \\
\hline $\begin{array}{l}\text { Pseudocolmo }(\mathrm{g}) \\
\text { Pseudostem }\end{array}$ & 0,41 & 6,06 \\
\hline $\begin{array}{l}\text { Sistema radicular }(\mathrm{g}) \\
\text { Root system }\end{array}$ & 0,20 & 1,19 \\
\hline $\begin{array}{l}\text { Razão de peso } \\
\text { foliar - RPF - }\left(\mathrm{g} \cdot \mathrm{g}^{-1}\right)^{1}\end{array}$ & $0,57^{\mathrm{A}}$ & $0,50^{\mathrm{B}}$ \\
\hline $\begin{array}{l}\text { Leaf weight ratio }-L W R \\
\text { Área foliar }\left(\mathrm{cm}^{2}\right) \\
\text { Leaf area }\end{array}$ & $320^{\mathrm{B}}$ & $2369^{\mathrm{A}}$ \\
\hline $\begin{array}{l}\text { Leaf area } \\
\text { Relação lâmina/colmo }\end{array}$ & $2,00^{\mathrm{A}}$ & $1,20 \mathrm{~B}$ \\
\hline $\begin{array}{l}\text { Leaf/stem ratio } \\
\text { Relação(PA/SR) } \\
A P / R S\end{array}$ & $6,04^{\mathrm{A}}$ & $11,24^{\mathrm{A}}$ \\
\hline $\begin{array}{l}\text { Folhas vivas/perfilho principal } \\
\text { Live leaves/main tiller }\end{array}$ & $5,3^{\mathrm{A}}$ & $3,0^{\mathrm{B}}$ \\
\hline $\begin{array}{l}\text { Perfilhos/planta } \\
\text { Tillers/plant }\end{array}$ & $4,9^{\mathrm{B}}$ & $8,6^{\mathrm{A}}$ \\
\hline $\begin{array}{l}\text { Comp. de folhas verdes do } \\
\text { perfilho principal }(\mathrm{mm}) \\
\text { Length of green leaves in } \\
\text { the main tiller ( } \mathrm{mm})\end{array}$ & $14.750^{\mathrm{B}}$ & $2541^{\mathrm{A}}$ \\
\hline
\end{tabular}

Valores entre parênteses correspondem ao peso residual da planta após o corte (Values between parenthesis represent residual plant weight after cut).

Médias seguidas de letras distintas diferem pelo teste Tukey $(P<0,05)$ (Means followed by different letters differ by Tukey test $[P<.05]$ ).

1 Peso de folhas/Peso da planta toda (Leaf weight/Whole plant weight).

2 PA - Parte aérea; SR - Sistema radicular (AP - Aerial part/RS - Root system). 
Tabela 2 - Contribuição percentual das frações folha, colmo e raiz para o peso total da planta às idades de 16 e 37 dias

Table 2 - Percentage contribution of the plant fractions. leaves, stem and root to the total plant weight at the ages of 16 and 37 days

\begin{tabular}{lcc}
\hline & \multicolumn{2}{c}{$\begin{array}{c}\text { Idade (dias) } \\
\text { Age (days) }\end{array}$} \\
\cline { 2 - 3 } $\begin{array}{l}\text { Fração da planta } \\
\text { Plant fractions }\end{array}$ & 16 & 37 \\
\hline $\begin{array}{l}\text { Folha } \\
\text { Leaf }\end{array}$ & $57 \%$ & $50 \%$ \\
$\begin{array}{l}\text { Colmo } \\
\text { Stem }\end{array}$ & $29 \%$ & $42 \%$ \\
Raiz & $14 \%$ & $8 \%$ \\
Root & & \\
\hline
\end{tabular}

perfilho (Gomide \& Gomide, 2000; Skinner \& Nelson, 1995; Davies et al., 1983; Robson, 1973). O comprimento médio das 5,3 folhas verdes aos 16 dias era de $27,8 \mathrm{~cm}$ contra $84,7 \mathrm{~cm}$ das três folhas verdes por perfilho aos 37 dias de idade.

Esta variação no comprimento médio das folhas com o nível de inserção está bem representada no trabalho de Gomide \& Gomide (2000), que avaliaram a morfogênese de cultivares de Panicum maximum, dentre eles a cultivar Mombaça. Estes autores relataram comprimentos em torno de 30 a $70 \mathrm{~cm}$ para as folhas de nível de inserção 1 e 6 , respectivamente.

Os valores de razão de peso foliar (RPF) encontrados neste trabalho, além de ligeiramente superiores aos relatados por Gomide \& Gomide (1999) para esta mesma espécie, também revelam diferenças entre idades, outro aspecto não observado por aqueles autores.
O número total de folhas aumentou de 6 para 12 do 13 ㅇ ao 69 o dia do crescimento seminal, enquanto o comprimento médio das folhas variou de $207 \pm 16 \mathrm{~mm}$ a $1080 \pm 48 \mathrm{~mm}$. Já o número de folhas vivas caiu para 3 por volta do $35^{\circ}$ dia, mantendo-se constante a partir desta data, corroborando os resultados de Gomide \& Gomide (2000).

A estabilização do número de folhas verdes por perfilho, quando o surgimento de novas folhas compensa a senescência das primeiras folhas, é sugerida como critério na determinação do momento de corte da planta e do período de descanso do pastejo rotacionado (Fulkerson et al., 1999; Fulkerson \& Slack, 1995; Grant et al., 1988). Entretanto, no presente estudo, o maior comprimento das últimas folhas expandidas mais do que compensaria a área foliar perdida por senescência e morte das primeiras folhas. De fato, Santos et al. (1999) observaram aumento no comprimento total de folhas vivas por perfilho das cultivares Mombaça e Tanzânia de Panicum maximum, em função do aumento no tamanho das folhas, à medida que o período de descanso aumentou de 28 para 38 e 48 dias. Rhodes (1969) observou que espécies de azevém de folhas maiores foram mais produtivas sob maiores intervalos de corte que as espécies de folhas mais curtas, o inverso sendo observado sob cortes freqüentes. Portanto, a adoção de variáveis isoladas, como início da senescência, para determinação do manejo pode levar a conclusões equivocadas (Lemaire \& Agnusdei, 1999). Daí a importância de associar características morfogênicas a índices de crescimento que revelem o estádio de desenvolvimento da planta (Calbo et al., 1989).

Tabela 3 - Taxas de aparecimento (TApF), alongamento (TAIF) e senescência (TS) foliares do perfilho principal e taxa de expansão da área foliar (TEAF) da planta de capim-Mombaça nos três crescimentos

Table 3 - Average leaf appearance rate (LAR), leaf elongation rate (LER) and leaf senescence rate (LSR) of main tiller and leaf area expansion rate (LAER) of Mombaçagrass in three growths

\begin{tabular}{|c|c|c|c|c|}
\hline $\begin{array}{l}\text { Crescimento } \\
\text { Growth }\end{array}$ & $\begin{array}{c}\text { TApF } \\
\text { (folhas/perf.dia) } \\
\text { LAR } \\
\text { (leaves/tiller.day) }\end{array}$ & $\begin{array}{c}\text { TAlF } \\
\text { (mm/perf.dia) } \\
\text { LER } \\
\text { (mm/tiller.day) }\end{array}$ & $\begin{array}{c}\text { TS } \\
\text { (mm/perf.dia) } \\
\text { LSR } \\
\text { (mm/tiller.day) }\end{array}$ & $\begin{array}{c}\text { TEAF } \\
\left(\mathrm{cm}^{2} / \text { planta.dia }\right) \\
\text { LAER } \\
\left(\mathrm{cm}^{2} / \text { plant.day }\right)\end{array}$ \\
\hline $\begin{array}{l}\text { Estabelecimento (C1) } \\
\text { Establishment }\end{array}$ & $0,100^{\mathrm{A}}$ & $88,4^{\mathrm{A}} \pm 7,8$ & $55,5 \pm 5,1$ & $72,0^{\mathrm{A}} \pm 4,6$ \\
\hline $\begin{array}{l}\text { Establishment } \\
\text { Rebrota (C2) } \\
\text { Regrowth }\end{array}$ & $0,104^{\mathrm{A}}$ & $87,8^{\mathrm{A}} \pm 13,9$ & $38,5 \pm 7,2$ & $73,7^{\mathrm{A}} \pm 2,6$ \\
\hline $\begin{array}{l}\text { Rebrota }(\mathrm{C} 3) \\
\text { Regrowth }\end{array}$ & $0,053^{\mathrm{B}}$ & $36,7^{\mathrm{B}} \pm 5,7$ & $17,9 \pm 6,1$ & $53,1^{\mathrm{B}} \pm 1,9$ \\
\hline
\end{tabular}

Médias seguidas por letras iguais não diferem $(P<0,05)$ pelo teste Tukey.

Different letters stand for difference $(P<.05)$ by Tukey test.

R. Bras. Zootec., v.32, n.4, p.795-803, 2003 
Durante os 66 dias de rebrotação após o corte ao 16 o dia de crescimento seminal, sete novas folhas completaram a expansão no perfilho, mas o número de folhas vivas se estabilizou em 3 por volta do $32^{\circ}$ dia, com comprimento médio de $1250 \pm 140 \mathrm{~mm}$.

$\mathrm{O}$ índice de área foliar (IAF) durante o crescimento de estabelecimento cresceu de 0,66 a 21,6 de forma assintótica, em função das idades (Figura 1) mas a intercepção da RFA estabilizou em $95 \%$ ao 42 o dia. Já no crescimento após corte aos 16 dias, o crescimento do IAF foi linear $(b=0,3 /$ dia; $r=0.97)$, variando de $0, \operatorname{logo}$ após o corte, a 19,8 ao 65 o dia, sendo que a intercepção luminosa se estabilizou em $96 \%$ a partir dos 240 dia (Figura 1). Este rápido alcance da máxima intercepção luminosa foi constatada também em condições de campo, o que comprova a acuidade desta estimativa.

Deve-se enfatizar a estabilização da intercepção da RFA apesar do aumento no IAF e também do peso da planta. $\mathrm{O}$ alongamento do colmo, processo precoce em gramíneas tropicais, favorece a penetração de luz no dossel, resultando na necessidade de maior área foliar para interceptar o mesmo percentual de RFA. Com isso tem-se uma estabilização da intercepção da radiação incidente, apesar dos crescentes valores de índice de área foliar. Esta melhor distribuição da luz ao

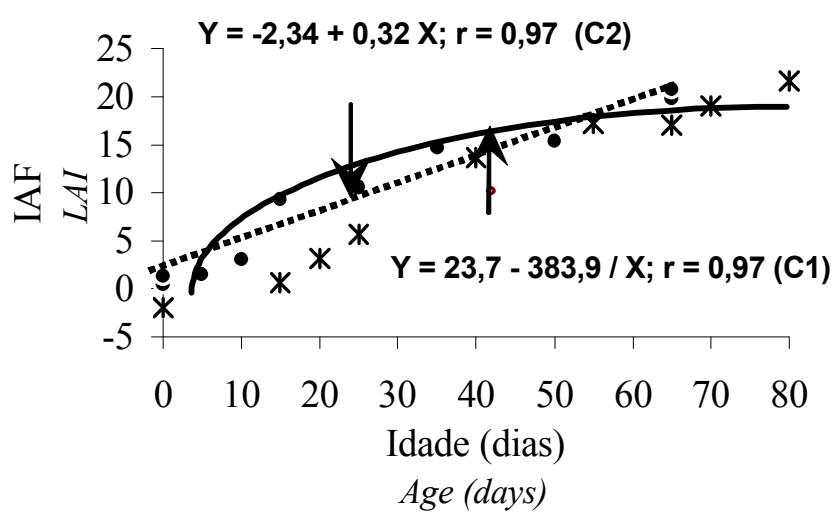

Figura 1 - Evolução do índice de área foliar (IAF) durante os crescimentos de estabelecimento $\left(C^{1 *}\right)$ e de rebrotação após corte aos 16 dias $\left(C^{2} \cdot\right)$ $\Leftarrow$ Flechas mostram o ponto de $95 \%$ de intercepção da Radiação Fotossinteticamente Ativa (RFA).

Figure 1 - Evolution of leaf area index (LAI) during the establishment $\left(C^{1 *}\right)$ and regrowth $\left(C^{2}\right.$ ) after a harvest taken on the $16^{\text {th }}$ day of establishment growth $\Leftarrow$ Arrows show the point of $95 \%$ interception of Photosynthetically Active Radiation (PAR). longo do perfil do dossel permite a chegada de RFA às folhas inferiores e assim previne ou retarda o início da senescência (Gan \& Amasino, 1997).

As taxas médias diárias de aparecimento e alongamento foliar por perfilho observadas no crescimento de estabelecimento (Tabela 3) repetem os dados de Gomide \& Gomide (2000). O corte ao 16o dia não afetou $(\mathrm{P}>0,05)$ estas taxas porém, redução em ambas as taxas ocorreu com o corte realizado ao 370 dia. Logicamente, o mesmo efeito foi observado para a taxa de expansão da área foliar (Tabela 3). A taxa de senescência foi também superior no crescimento de estabelecimento, caindo nos crescimentos seguintes, o que reflete a menor vida útil das primeiras folhas. Além disso, o maior período de crescimento (83 dias) durante o estabelecimento concorreria para tal observação, por permitir maior tempo de acompanhamento da senescência. Também, o próprio ritmo de crescimento da planta, com altas taxas de aparecimento e alongamento foliares, favorece a senescência das folhas primeiramente formadas, uma vez que aumenta a competição por luz e assimilados. Apesar da menor taxa de senescência foliar, o crescimento 3 apresentou menor taxa de recuperação da área foliar (Figura 2). Assim, no balanço alongamento senescência, menores valores correspondem ao crescimento após corte ao 370 dia.

Comportamento semelhante às taxas de aparecimento e alongamento foliares foi observado em relação aos índices fisiológicos TCR, TAL e RAF (Tabela 4). Embora o corte represente um estresse para a planta,

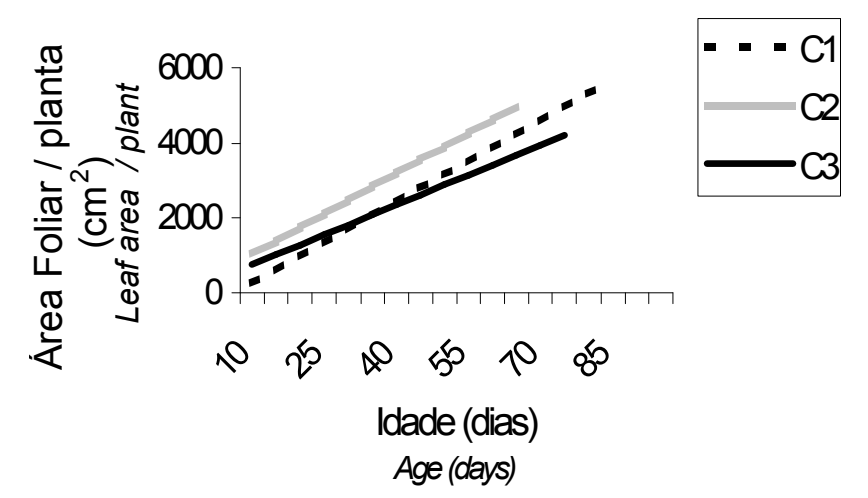

Figura 2 - Evolução da área foliar verde por planta em três crescimentos.

Figure 2 - Evolution of green leaf area per plant in three growths. 
aquele realizado ao $16^{\circ}$ dia não comprometeu as duas primeiras taxas, sendo que apenas a RAF apresentou baixos valores nos dias iniciais da rebrota, fato decorrente da própria natureza deste índice (Área Foliar / Peso Total). Porém, graças à rápida emissão de novas folhas e devido ao baixo peso da planta, os valores de RAF se elevaram rapidamente.

Como mostrado pelos índices do crescimento de estabelecimento (Tabela 4), no momento do corte ao $16^{\circ}$ dia a planta se encontra em fase de intenso crescimento, com altos valores de RAF, TCR e TAL; indicando um grande investimento em material foliar. Esta alocação preferencial de substratos para a produção de folhas se mantém após o corte, e, combinada com a não decaptação dos perfilhos, proporciona rápido crescimento da RAF (Tabela 4), da taxa de expansão da área foliar (Tabela 3; Figura 2) e, conseqüentemente, do índice de área foliar (Figura 1).

Por outro lado, o corte realizado ao 370 dia de idade ocorreu num momento em que a alocação de substratos para o crescimento foliar não era tão intensa. Apesar da maior relação PA/SR a esta idade, a diminuição da relação folha/colmo revela o crescimento preferencial do colmo. Por isso, menores valores são observados para a RPF nesta idade (Tabela 1).

O comprometimento do crescimento $\mathrm{C} 3$ pode ser visualizado na Figura 2, que mostra incrementos semelhantes e mais altos valores de área foliar para os dois primeiros crescimentos, relativamente ao $\mathrm{C} 3$, resultante da mais lenta recomposição da área foliar no terceiro crescimento. Tal fato é explicado por menores taxas de aparecimento e alongamento foliares deste período (Tabela 3 ).

De maneira geral, os valores médios de TCR, TAL e RAF caíram com o avanço da idade. Este fato, aliado à senescência e morte de tecidos (Tabela 3) responde pela estabilização no acúmulo de matéria seca após algumas semanas de crescimento. Vale ressaltar o alto valor da TAL e baixos valores de TCR e RAF nos primeiros 3 dias de rebrota do crescimento C2. A TAL, representando o balanço entre ganho fotossintético e perda respiratória de carbono (Lambers, 1987), mostra não ter havido balanço negativo e conseqüente perda de peso. A baixa demanda respiratória, em razão da pouca biomassa à idade de 16 dias e o rápido surgimento de folhas novas com alta capacidade fotossintética (Woledge \& Leafe, 1976; Gomide et al., 2002) explicam estes altos valores da TAL (Lambers et al., 1989).
Por outro lado, vale ressaltar os valores negativos de TAL e TCR no início da rebrota do crescimento C3, revelando a alta demanda respiratória decorrente da maior biomassa do material residual. Tal observação está em consonância com o balanço negativo de carbono relatado por Davidson \& Milthorpe (1966) no início da rebrota de Dactylis glomerata, após desfolha intensa. Ao mesmo tempo, a redução nas taxas de aparecimento e alongamento foliares, comprovada pelo comprometimento da RAF, prolonga e acentua o déficit de carbono da planta. Assim, apenas entre a segunda e a terceira semanas de rebrotação, a planta conseguiu restabelecer o balanço positivo de carbono e com isso voltar a crescer, apresentando valores positivos de TCR (Tabela 4).

Observou-se relação negativa entre TAL e IAF, de comportamento assintótico (Figura 3), consistente com o conceito de uma faixa de IAF na qual a taxa de crescimento cultural (Brown \& Blaser, 1968) e a taxa de produção de forragem (Bircham \& Hodgson, 1983; Parsons et al. 1983) são máximas.

Analisando o crescimento de cultivares de Panicum maximum, Gomide \& Gomide (1999) descreveram comportamento semelhante da TAL em função do avanço da idade. Segundo estes autores, a queda na TAL se deve à competição por luz, ao avanço na idade média da área foliar da planta e ao incremento das demandas respiratórias.

É difícil estabelecer uma relação causa-efeito entre os índices fisiológicos e as características morfogênicas como TAlF e TApF, ou seja, explicar se os valores negativos de TAL e TCR observados durante o $\mathrm{C} 3$ se devem às baixas taxas de aparecimento e alongamento foliares ou o inverso. Como em nenhum dos cortes houve decapitação de perfilhos, a diferença na velocidade de emissão de folhas pelo meristema apical após o corte se deve a outros fatores.

A maior intensidade da desfolha das plantas após o corte do crescimento $\mathrm{C} 3$, gerando valores negativos de TAL e TCR, estaria a representar o consumo de reservas para atender a maior demanda de energia para manutenção e rebrotação. O maior peso médio das plantas à idade de 37 dias, associado a mesma altura de corte, resultou em maior intensidade de desfolha nesta idade, relativamente à idade de 16 dias. Diversos trabalhos mostram o efeito da intensidade de desfolha sobre o consumo de reservas e a recuperação após o corte (Ryle \& Powell, 1975; Davies, 1974; Davidson \& Milthorpe, 1966; Gomide 
Tabela 4 - Valores médios para taxa de crescimento relativo $\left(\mathrm{g} \cdot \mathrm{g}^{-1} \cdot \mathrm{dia}^{-1}\right)$, taxa assimilatória líquida $\left(\mathrm{g} \cdot \mathrm{m}^{-2} \cdot\right.$ dia $\left.{ }^{-1}\right)$ e razão de área foliar $\left(\mathrm{m}^{2} \cdot \mathrm{kg}^{-1}\right)$ do capim-mombaça em três crescimentos

Table 4 - Mean Relative Growth Rate (RGR - g. $g^{-1}$.dia $\left.{ }^{-1}\right)$, Mean Net Assimilation Rate (NAR -g.m ${ }^{-2}$.dia ${ }^{-1}$ ) and Mean Leaf Area Ratio $\left(L A R-\mathrm{m}^{2} \cdot \mathrm{kg}^{-1}\right)$ of Mombaçagrass in three growths

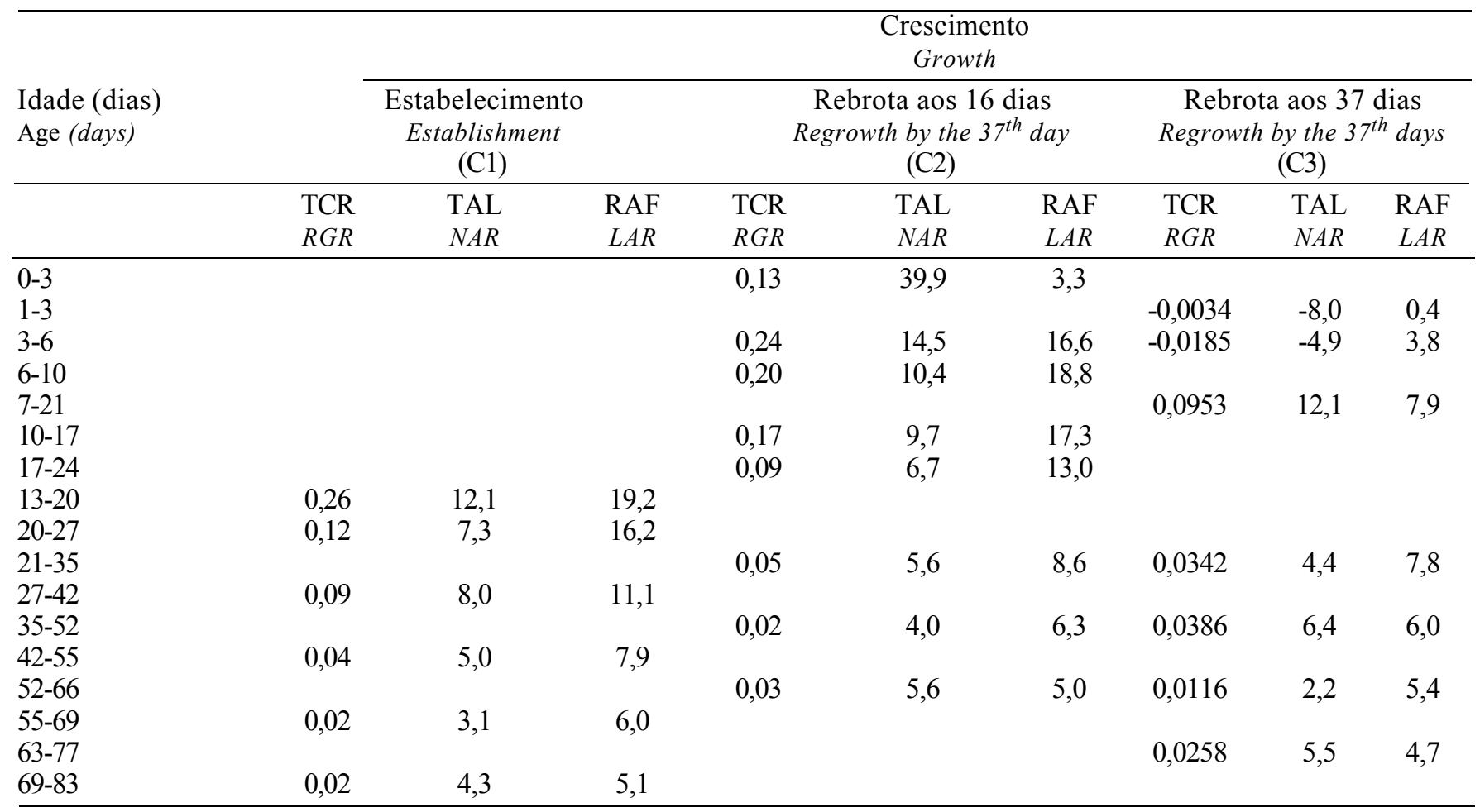

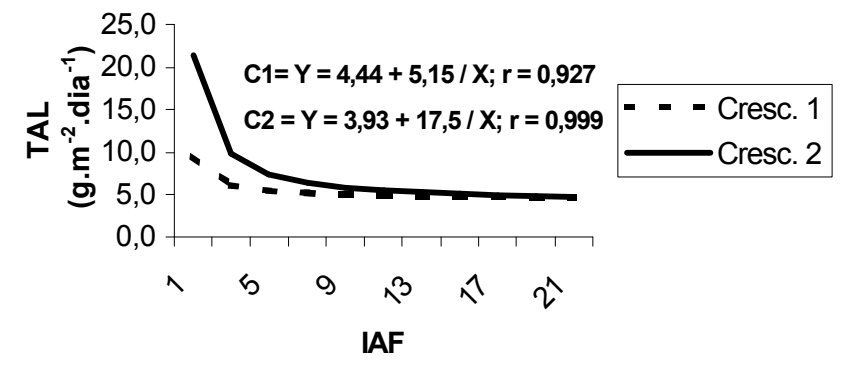

Figura 3 - Relação entre a taxa assimilatória líquida (TAL) e o índice de área foliar (IAF).

Figure 3 - Relation between net assimilation rate (NAR) and leaf area index (LAI).

et al., 2002). Diferentes intensidades de desfolha do perfilho principal do capim-mombaça resultaram em diferenças, tanto no consumo de reservas, como na TCR da rebrota (Gomide et al., 2002). Resultado semelhante foi encontrado por Ryle \& Powell (1975), em plantas de cevada.

Os dados do presente estudo não permitem inferir a respeito da interação de índices de crescimento e características morfogênicas. Contudo, fica clara a estreita relação entre ambos, sendo este um campo interessante para novas pesquisas com estas e outras espécies tropicais carentes deste tipo de estudo.

\section{Conclusões}

As características morfogênicas tem valores mais altos durante o crescimento de estabelecimento que a rebrotação após corte na fase final do estabelecimento da planta.

A desfolha na fase final de estabelecimento causa intenso estresse à planta, isto é, balanço negativo de carbono, caracterizado por atraso na recuperação de sua área foliar, em decorrência de valores inicialmente negativos de índices de crescimento e comprometimento das características morfogênicas do perfilho.

\section{Literatura Citada}

BEADLE, C.L. Growth analysis. In: HALL, D.O.; BOLHARNORDENKAMPF, H.R.; LEE GOOD, R.C. et al. (Eds.) Photosynthesis and production in a change enviroment: a field and laboratory manual. London: 1993. p.36-46. 
BIRCHAM, J.S.; HODGSON, J. The influence of sward condition on rates of herbage growth and senescense in mixed sward under continuous stocking management. Grass and Forage Science, v.38, n.4, p.323-331, 1983.

BROWN, R.H.; BLASER, R.E. Leaf area index in pasture growth. Herbage Abstract, v.38, n.1, p.1-9, 1968.

CALBO, A.G.; SILVA, W.L.C.; TORRES, A.C. Comparação de modelos e estratégias para análise de crescimento. Revista Brasileira de Fisiologia Vegetal, v.1, p.1-7, 1989.

CHAPMAN, D.F.; LEMAIRE, G. Morphogenetic and structural determinants of plant regrowth after defoliation. In: INTERNATIONAL GRASSLAND CONGRESS, 17. 1993, Australia. Proceedings... Australia: s.ed. 1993, p.95-104.

COSTA, L.C.; MORISON, J.; DENNETT, M. Effects of the weather on growth and radiation intercepted by Faba bean. Pesquisa Agropecuária Brasileira, v.32, n.3, p.277-281, 1997.

DAVIES, A. Leaf tissue remaining after cutting and regrowth in perennial ryegrass. Journal of Agriculture Science, v.82, p.165-172, 1974.

DAVIES, A.; EVANS, M.E.; EXLEY, J.K. Regrowth of perennial ryegrass as affected by simulated leaf sheaths. Journal of Agricultural Science, v.77, p.131-137, 1983.

DAVIDSON, J.L.; MILTHORPE, F.L. The effect of defoliation on the carbon balance in Dactylis glomerata. Annals of Botany, v.30, n.118, p.185-198, 1966.

FULKERSON, W.J.; SLACK, K. Leaf number as a criterion for determining defoliation time for Lolium perenne. 2 - Effect of defoliation frequency and height. Grass and Forage Science, v.50, n.1, p.16-20, 1995.

FULKERSON, W.J.; SLACK, K.; HAVILAH, E. The effect of defoliation interval and height on growth and herbage quality of kikuyu grass (Pennisetum clandestinum). Tropical Grassland, v.33, 138-145, 1999.

GAN, S.; AMASINO, R.M. Making sense of senescense Molecular genetic regulation and manipulation of leaf senescence. Plant Physiology, v.113, p.313-319, 1997.

GOMIDE, C.A.M.; GOMIDE, J.A. Análise de crescimento de cultivares de Panicum maximum Jacq. Revista Brasileira de Zootecnia, v.28, n.4, p.675-680, 1999.

GOMIDE, C.A.M.; GOMIDE, J.A. Morfogênese de cultivares de Panicum maximum Jacq. Revista Brasileira de Zootecnia, v.29, n.2, p.341-348, 2000.

GOMIDE, C.A.M.; GOMIDE, J.A.; MARTINEZ, C.A. et al. Fotossíntese, reservas orgânicas e rebrota do capim-mobaça (Panicum maximum, Jacq.) sob diferentes intensidades de desfolha do perfilho principal. Revista Brasileira de Zootecnia, v.31, n.6, p.2165-2175, 2002.

GRANT, S.A.; BARTHRAM, G.T.; KING, L.T.J. et al. Comparison of herbage production under continuous stocking and intermittent grazing. Grass and Forage Science, v.43, n.1, p.29-39, 1988.

HARPER, J.L. Population biology of plants. San Diego: Academic Press, 1977. 892p.

HAY, R.K.M.; WALKER, A.J. An introduction to the physiology of crop yield. England: Longman Group, 1989. 292 p.

KRAUSS, E.; WILSON, D.; ROBSON, M.J. Respiration: correlation with growth rate and its quantitative significance for net assimilation rate and biomass production. In: LAMBERS, H.; CAMBRIDGE, M.L.; KONINGS, H. et al. (Eds.) Causes and consequences of variation in growth rate and productivity of higher plants. Hague: Netherlands, 1989. p.187-198.

R. Bras. Zootec., v.32, n.4, p.795-803, 2003
LAMBERS, H. Does variation in photosynthetic rate explain variation in growth rate? Netherlands Journal Agricultural Science, v.35, p.505-519, 1987.

LAMBERS, H.; FREIDJEN, N.; POORTER, H. et al. Analysis of growth based on net assimilation rate and nitrogen productivity. Their physiological background. In: LAMBERS, H.; CAMBRIDGE, M.L.; KONINGS, H. et al. (Eds.) Causes and consequences of variation in growth rate and productivity of higher plants. Hague: Netherlands, 1989. p.1-17.

LAWLOR, D.W. Photosynthesis, productivity and environment. Journal of Experimental Botany, v.46, p.1449-1461, 1995 (special issue).

LEMAIRE, G.; AGNUSDEI, M. Leaf tissue turn-over and efficiency of herbage utilisation. In: PROCEEDINGS OF INTERNATIONAL SYMPOSIUM "GRASSLAND ECOPHYSIOLOGY AND GRAZING ECOLOGY”, 1999, Curitiba. Proceedings... Curitiba: UFPR, 1999. p.165-186.

PARSONS, A.; LEAFE, E.L.; COLLET, B. The physiology of grass production under grazing. I - Characteristics of leaf and canopy photosynthesis of continuously grazed sward. Journal Apply Ecology, v.20, n.1, p.1117-126. 1983.

PARSONS, A.J.; PENNING, P.D. The effect of duration of regrowth on photosynthesis, leaf death and average rate of growth in a rotational grazed sward. Grass and Forage Science, v.43, n.1, p.15-27, 1988.

POTTER, J.R.; JONES, J.W. Leaf area partitioning as an important factor in growth. Crop Science, v.20, p.10-14, 1976.

POORTER, H. Interspecific variation in relative growth rate: on ecological causes and physiological consequences. In: LAMBERS, H.; CAMBRIDGE, M.L.; KONINGS, H. et al. (Eds.) Causes and consequences of variation in growth rate and productivity of higher plants. Hague: Netherlands, 1989. p.45-67.

RADFORD, P.J. Growth analysis formulae: their use and abuse. Crop Science, v.7, n.3, p.171-175, 1967.

RYLE, G.J.A.; POWELL, C.E. Defoliation and regrowth in the graminaceous plant: The role of current assimilate. Annals of Botany, v.39, p.297-310, 1975.

ROBSON, M.J. The growth and development of simulated sward of perennial ryegrass. II - Carbon assimilation and respiration in a seedling sward. Annals of Botany, v.37, n.151, p.501-518, 1973.

RHODES, I. The relationship between productivity and some components of canopy structure in ryegrass (Lolium spp.). I - Leaf length. Journal of Agricultural Science, v.73, p.315-319, 1969.

SANTOS, P.M.; BALSALOBRE, M.A.A.; CORSI, M. Uso do número de folhas por perfilho no manejo de Panicum maximum cvs. Mombaça e Tanzânia. In: REUNIÃO ANUAL DA SOCIEDADE BRASILEIRA DE ZOOTECNIA, 36., 1999. Porto Alegre. Anais... São Paulo: SBZ/Gmosis, [1999] 17 par. CD-ROM. Forragicultura.

SKINNER, R.H.; NELSON, C.J. Elongation of the grass leaf and its relationship to the phylochron. Crop Science, v.34, n.1, p.4-10, 1995.

WOLEDGE, J.; LEAFE, E.L. Single leaf and canopy photosynthesis in a ryegrass sward. Annals of Botany, v.40, n.68, p.773-783, 1976.

Recebido em: 28/05/02 Aceito em: 09/12/02 